\title{
In vitro regeneration of multiple shoots from encapsulated somatic embryos of Artemisia vulgaris $\mathbf{L}$.
}

\author{
M. S. Sudarshana*, Rajashekar N, Niranjan M. H. and \\ Rezwan Karami Borzabad \\ Plant Tissue Culture Laboratory, Department of Studies in Botany, University of Mysore, Manasagangothri, \\ Mysore - 570006, Karnataka, India.
}

\begin{abstract}
A protocol has been established for plant regeneration from encapsulated somatic embryos of Artemisia vulgaris L. Encapsulated somatic embryo of A. vulgaris gave better response at $2 \%$ alginate, $75 \mathrm{mM}$ calcium chloride hardened for 30 minutes. Morphogenic response and percentage of conversion into plantlets of encapsulated beads on storage and temperature effect were studied. Further, encapsulated somatic embryo retrieved from storage conditions was evaluated for its viability. The encapsulated embryos can be stored upto 4 months at $4^{\circ} \mathrm{C}, 20^{\circ} \mathrm{C}$ and $22^{\circ} \mathrm{C}$. Maximum conversion frequency of $90 \%$ was observed from encapsulated somatic embryos cultured on MS medium supplemented with $G A_{3}(1.5 \mathrm{mg} / \mathrm{l}), \mathrm{IAA}(0.5 \mathrm{mg} / \mathrm{l})$ and Ascorbic acid $(40 \mathrm{mg} / \mathrm{l})$ and $22^{\circ} \mathrm{C}$ temperature was found to be optimum irrespective of storage periods. In the present investigation, the development of multiple shoots from a single synthetic seed is a recent record.
\end{abstract}

Keywords: Artemisia, somatic embryo, encapsulation, synthetic seeds, cold storage.

Abbreviations: BAP-benzylaminopurine; GA - gibberellic acid; MS-Murashige and Skoog medium.

Submitted Date 18 June 2013

Accepted Date: 24 June

\section{Introduction}

Artemisia vulgaris, of Asteraceae, is a shrubby, aromatic perennial herb, indigenous to India. The investigations of mugwort extracts indicated a hepatoprotective activity and for various liver disorders (Gilani et al. 2005 [1]). The plant is alexiteric, appetizer, cures "Kapha", asthma and itching. It is useful for stomachic, deobstruent and antispasmodic. The extract of leaves and stem tips are administered in certain diseases of children, such as convulsions, measles and disease of the brain (Kirtikar and Basu, 1935 [2]).

In traditional medicine, this plant is being widely used for the treatment of diabetes (Walter et al. 2003 [3]), (Sun et al. 1992 [4]) found that artemisinin extracted from A. vulgaris had antitumor activity, (Judzentience and Buzelyte 2006 [5] ) have reported that essential oils of this plant are used for their insecticidal, antimicrobial and antiparasitical properties. Several medicinally active components of A. vulgaris have been identified including vulgrin, quercetin, coumarins, sesquiterpene lactones, volatile oils and insulin (USDA - ARS - NGRL, 2004[6]). Plant tissue culture is a well known biotechnological tool for the rapid propagation of medicinal plants for the purpose of commercialization (Kitto 1997 [7] ) and cryopreservation (Decruse et al. 1999 [8]). Somatic embryogenesis and organogenesis have been the common pathways for the clonal propagation of superior medicinal plant species (Gray and Brent 1986 [9]). Somatic embryos have been recognized as an attractive tool for synthetic seed production and mass propagation of elite genotypes (Redenbaugh et al. 1991 [10]). The advantages of using artificial seeds include large scale production at low cost and subsequent propagation, ease of handling, transportation and potential storage, (Redenbaugh 1990[11], Rao et al. 1998 [12]). Synthetic seed consists of either a quiescent or nonquiescent somatic embryo with or without a protective encapsulation (Gray and Purohit 1991 [13]).

An efficient micropropagation system and subsequent rooting were developed for A. vulgaris (Sujatha and Ranjitha Kumari 2007 [14]). Further they also reported that nodal segments were excised for proliferating shoot culture and encapsulated to produce higher quality encapsulated nodal segments. All encapsulated nodal segments survived 20 weeks of $5^{\circ} \mathrm{C}$ storage, providing a cost effective cold storage for alginate encapsulated vegetative (node) explant of mugwort.

In vitro regeneration is an important tool in conservation, as it provides complimentary conservation options for plant species with limited reproductive capacity (Pandey et al. 1993 [15]). Successful plant regeneration and synthetic seeds have been established in cereals, vegetables, fruits, ornamentals, aromatic grass and conifers (Fowke et al. 1994 [16]; Janeiro et al. 1997[17]; Mamiyo and Sakamoto 2001 [18]; Ganapathi et al. 
In vitro regeneration of multiple shoots from encapsulated somatic embryos of Artemisia vulgaris $L$.

2001[19]; Brishia et al. 2002 [20]). The present study aims at in vitro regeneration of multiple shoots from encapsulated somatic embryos of Artemisia vulgaris L. - a tool for germplasm conservation.

\section{Materials and Methods:}

Source Material : Embryogenic callus of Artemisia vulgaris L. (Leaf explants) maintained for 2-4 week on MS basal medium (Murashige and Skoog 1962 [21]) supplemented with 2,4-D (0.5mg/l), BAP (1mg/l) and Ascorbic acid $(50 \mathrm{mg} / \mathrm{l})$ were sub-cultured to liquid medium. Later suspension of embryo/embryoids and its aggregates were obtained after subjecting to agitation on platform shaker.

Encapsulation : Eight weeks after the beginning of standard subculture, embryos of various shapes (Fig: $1 \mathrm{a}, \mathrm{b}, \mathrm{c})$ were removed from embryo suspension. The isolated embryos were inserted into sodium alginate (2-4\%) drop, with the help of fine forceps and dropped into a solution of $50-80 \mathrm{mM}$ calcium chloride solution; hardened for 20-30 minutes at room temperature with occasional stirring. Later calcium chloride solution was decanted and encapsulated embryos were washed with sterile distilled water. These synthetic seeds were dried on sterile filter paper, later subjected to germination directly or after storage period on MS medium supplemented with various concentrations $(0.5,1.0,1.5$ and $2.0 \mathrm{mg} / \mathrm{l})$ of growth regulators $\mathrm{BAP}, \mathrm{Kn}$ and $\mathrm{GA}_{3}$ individually and combination of BAP+ NAA $(0.5+0.5 ; 0.5+1.5 ; 0.5+2.0 ; 1.0+.05 ; 1.0+1.0 ; 1.0+1.5$ and $1.0+2.0 \mathrm{mg} / \mathrm{l}) ; \mathrm{BAP}^{2} \mathrm{GA}_{3}$ $(0.5+0.5 ; 0.5+1.0 ; 1.0+1.0) \mathrm{GA}_{3}+\mathrm{IAA}+$ Ascorbic acid $(0.5+0.5+40 ; 1.0+0.5+40 ; 1.5+0.5+40 \mathrm{mg} / \mathrm{l})$.

To study the effect of storage period (1month, 2 month and 4 month) and temperature $\left(4^{\circ} \mathrm{C}, 20^{\circ} \mathrm{C}\right.$ and $\left.25^{\circ} \mathrm{C}\right)$ on germination, the capsules were stored at $4^{\circ} \mathrm{C}$ in a refrigerator on moist filter paper in sterile petridishes for 0,1 , $3,5,7,10,15,18,20,20$ and 25days and thereafter germinated on MS medium. Storage was done in the dark by covering the petridishes with aluminum foil.

The germination frequency and the number of plants per capsule were recovered 6 weeks after culture on the germination medium. The number of plants developed from each capsule was determined by counting the plants under stereomicroscope.

Germinated synthetic seeds with well developed roots and shoots were initially transferred to pods containing soilrite with nutrient solution and hardening was carried out by covering with polythene bags. Gradually polythene bags were removed and the plants were planted in soil and kept under green house condition.

Statistical Analysis: All the experiments were repeated thrice and twenty replicates were employed for each treatment. The data were analyzed using SPSS. Analysis of variance (ANOVA) was used to test the statistical significance and the significance of differences among means was carried out using Tukey's test at $5 \%$ probability level.

\section{Results and Discussion :}

The capsule containing embryos of various shapes (Fig. d) showed sign of germination 6-7 days of culture (Fig. e). The alginate matrix ruptured and multiple shoot formation from a single synthetic seed is a recent record (Fig. f). In the present investigation, percentage of development of shoots from the encapsulated somatic embryo was compared between very low (2\%) and high (4\%) concentration of sodium alginate (Table 1). It was found that high concentration (4\%) of alginate, dropped in $75-80 \mathrm{mM}$ Calcium chloride for 20-30 minutes, were too hard, for somatic embryos to rupture (53\% germination). At $2 \%$ sodium alginate dropped in $75 \mathrm{mM} \mathrm{CaCl}_{2}$ for 30 minutes, appreciating result were obtained (84\% plantlet development)

Alginate is one of the most common polymers used for the immobilization of plant cells and production of synthetic (artificial) seeds because of non-toxic, inert, cheap and easily manipulable qualities (Endress 1994 [22]). However, higher and lower concentration of alginate shows greater variation in viscosity, which result in difficulty in decanting and encapsulation. Hence alginate concentration $(1-4 \%)$ in $50-80 \mathrm{mM}$ $\mathrm{CaCl}_{2}$ range needs to be optimized depending on type of material for best response. In this view several reports have published supporting 2.5\% alginate in Leptadenia reticulate (Molly et al. 2002 [23]), Apple (Micheli et al. 2002 [24] Carica papaya (Castillo et al. 1998 [25]), Eleusine coracana (George and Eapen 1995 [26]) and in Carrot (Timbert et al. 1995 [27]) and Centaurium rigualii (Benito et al. 1992 [28]). On contrary (Monica et al. 2005 [29]) have achieved successful germination in Rhodiola kirilowii at $4 \%$ and 5\% of sodium alginate. The present investigation was carried out with somatic embr

yo from suspension culture of fragile callus and hence low concentration $2 \%$ alginate and $75 \mathrm{mM} \mathrm{CaCl}_{2}$ gave better response. Conversion frequency of shoot is directly dependant on storage period (1,2 and 4 month) and temperature $\left(4^{\circ} \mathrm{C}, 20^{\circ} \mathrm{C}\right.$ and $\left.25^{\circ} \mathrm{C}\right)$ is as mentioned in Table-2. Higher emergence of encapsulated somatic embryo was recorded at storage period (1 month) $64.3,71.0$ and 88.7 percent conversion at $4^{\circ} \mathrm{C}, 20^{\circ} \mathrm{C}$ and $25^{\circ} \mathrm{C}$ respectively. With further increase in storage period, decline in percentage of germination was observed. $22^{\circ} \mathrm{C}$ temperature was found to be optimum irrespective of storage period. The encapsulated embryo showed high 
In vitro regeneration of multiple shoots from encapsulated somatic embryos of Artemisia vulgaris $L$.

germination frequency when stored (room temperature) for few days (0-3) with 96.34 - 93.18 percent germination and thereafter declined 87.5 - 29.57 percent germination, when stored for 5 - 25 days (Table-3) similar interpretation has been reported in Populus (Hausman et al. 1994 [30]), Quercus petrea and Q. robus, Janeiro et al. 1995[31]) and nodal explants of A. vulgaris (Sujatha and Ranjitha Kumari 2008 [32]) for in vitro culture, stored at temperature $\left(\mathrm{Cold}-5^{\circ} \mathrm{C}\right.$ and $25^{\circ} \mathrm{C}$ ) with different illumination. As growth during storage is not desirable the present investigation was carried out in dark condition. MS medium supplemented with growth regulator both individually and in combination gave best embryonic response (Table-4). Similar observations are made by (Naik and Chand 2006 [33]) and (Geetha et al. 2006 [34]) for encapsulated shoot tips of Punica granatum and Spilanthes acmella respectively. The decline in embryogenic response of encapsulated embryo may be due to oxygen deficiency and rapid drying of gel capsule. The regenerated plantlets were transferred to sterile soilrite for hardening and acclimatized plants were planted in field.

To summarize, the encapsulated somatic embryo showed multiple shoots from a single synthetic seed, which is recent record. Encapsulated somatic embryo of A. vulgaris gave better response at concentration $2 \%$ alginate, $75 \mathrm{mM} \mathrm{CaCl}_{2}$ hardened for 30 minutes and $22^{\circ} \mathrm{C}$ temperature was found to be optimum irrespective of storage periods.

\section{References}

[1]. AH Gilani, S Yaeesh, Q Danial and Ghayur MN. Hepatoprotective activity of aqueous-methanol extract of Artemisia vulgaris. Phytotherapy Research 19,2005,170-172.

[2]. KR Kirtikar and BD Basu. Indian Medicinal Plants ( $2^{\text {nd }}$ Edition Vol. II, International Book Distributors 1935)1395-1396.

[3]. HL Walter, PF Memory. and L.Elvin 2003. Medicinal Botany In: Plants affecting human health. (2 ${ }^{\text {nd }}$ ed. John Wiley and Sons Inc.) 354 .

[4]. USDA - ARS- NGRL 2004. Dr. Duke's Phytochemical and Ethnobotanical Databases. http://www.ars-gnir.gov/duke/chemactivities.html.

[5]. WC Sun, JX Han, WY Yang, DA Deng, and XF Yue. 1992. Antitumor activities of 4 derivaties of artemisic acid and artemisinin B In vitro. Acta pharmacologica Sinica. 13: 541-543

[6]. A Judzentience, and J . Buzelyte. 2006. Chemical composition of essential oils of Artemisia vulgaris L. (mugwort) from North Lithuania. Chemija. 17: 12-15.

[7]. SL Kitto 1997. Commercial Micropropagation. Horticultural Science 32, 1012-1014.

[8]. S Decruse, S Seeni and P Pushpangadan. 1999. Effect of cryopreservation on seed germination of selected rare medicinal plants of India. Seed Science and Technology 27: 501-505.

[9]. AT Gray, and HM Brent. 1986. Establishing a micropropagation system for American ginseng (Panax quinquiefolium). Horticultural Science 21: 232-236.

[10]. K Redenbaugh, JA Fuji, and D Slade. 1991. Synthetic seed technology. In vasil I.K. (Ed.) Cell culture and somatic cell genetics of plants. Acad. Press, 8: 35-74.

[11]. K Redenbaugh. 1990. Application of synthetic seeds to tropical crops. Horticultural Science 25, 251-255.

[12]. PS Rao, P Suprasanna, TR Ganapathi, and VA Bapat. 1998. Synthetic seeds: Concept, methods and applications, In: plant tissue culture and molecular biology, edited by Srivastava, P.S. (Narosa Publishing, New Delhi), 607-619.

[13]. AT Gray, and A Purohit. 1991. Establishing a microropagation system for American ginseng. Critical Review of Plant Science, 10: 33-61.

[14]. G Sujatha, and BD Ranjitha Kumari. 2007. Effects of phytohormones on micropropagation of Artemesia vulgaris L. Acta physiologiae Plantarum, 29:189-195.

[15]. NK Pandey, KC Tewari, RN Tewari, GC Joshi, VN Pandey, and G Pandey 1993. Medicinal plants of Kumaon Himalaya: strategies for conservation. In: Dhar, U. (Ed.) Himalayan Biodiversity Conservation Strategies. Himavikas Publications, Nainital, pp. 293-302.

[16]. LC Fowke, SM Attree and MK Pometry. 1994. Production of vigorous desiccation-tolerant white spruce (Picea glauca \{Moench Voss) synthetic seeds in a bioreactor. Plant Cell Report, 13: 601-606.

[17]. LV Janeiro, A Ballester, and AM Vieitez. 1997. In vitro response of encapsulated somatic embryos of camellia. Plant Cell Tissue Organ Culture, 54: 119-125.

[18]. George Leela and Eapen Susan, 1995. Encapsulation of somatic embryos of finger mittet, Eleusine coracana Gaertn. Indian Journal of Experimental Biology, 33: 291.

[19]. K Mamiyo, and Y Sakamoto. 2001. A method to produce encapsulatble units for synthetic seeds in Asparagus officinalis. Plant Cell Tissue Organ and Culture. 64: 27-32.

[20]. TR Ganapathi, I Srinivas, P Suprasanna, and VA Bapat. 2001. Regeneration of plants from alginated-encapsulated somatic embryos of banana cv Rasthali (Musa spp. AAB group). Biology of Plant. 37:78-181.

[21]. R Brishia, E Piccioni, and A Standardi. 2002. Micropropagation and synthetic seeds in M26 apple rootstock (II): A new protocol for production of encapsulated differentiating propagules. Plant Cell Tissue and Organ Culture, 68: 137-141.

[22]. T Murashige, and F Skoog. 1962. A revised medium for growth and bioassay with tobacco tissue cultures. Plant Physiology, 15: 473-497.

[23]. Endress. Plant cell Biotechnolgy. Springer-Verlag. (Berlin Heidelberg 1994)

[24]. Molly Hariharan, Delse Psebastian, Bnailas Benjamin and P.Prashy. 2002. Somatic embryogenesis in Leptadenia reticulate Wight \& Arn. A medicinal plant. Phytomorphology 52(2\&3):155

[25]. M Micheli, E Pellegrinos Piccioni, and A Standardi. 2002. Effects of double encapsulation and coating on synthetic seed conversion in m.26 apple rootstock. J. Microencapsulation 19: 347

[26]. B Castillo, MAL Smith, and UL Yadava. 1998. Plant regeneration from encapsulated somatic embryos of Carica papaya L. Plant Cell Reports, 17: 172-176.

[27]. R Timbert, JN Borbotin, A Kersulec, C Bazinet, and D Thomas. 1995. Physico-chemical properties of the encapsulation matrix and germination of carrot somatic embryos. Biotechnology and Bioengineering. 46: 573-578.

[28]. MEG Benito, C Perez, and AB Viviani. 1997. Cryopreservation of nodal explants of an endangered plant species (Centaurium rigualii Esteve) using the encapsulation-dehydration method. Biodiversity and conservation 6: 583-590. 
In vitro regeneration of multiple shoots from encapsulated somatic embryos of Artemisia vulgaris $L$.

[29]. Monica Zych, Mirosowa, Furmanowa, K Anna. Rajeskapatan, Anna Owicka, Mariola Dreger and Sywil Mendlewska. 2005. Micropropagation of Rhodiola kirtilowii. Plant using encapsulated auxiliary buds and callus. Acta Bilogia Cracoviensia series Botanica, 47(2): 88

[30]. JF Hausman, O Neys, C Kevers, and TH Gaspar. 1994. Effect of in vitro storage at $4^{\circ} \mathrm{C}$ on survival and proliferation of poplar shoots. Plant Cell Tissue and Organ Culture,38: 65-67.

[31]. LV Janeiro, AM Vieitez, and A Ballester. 1995. Cold storage of in vitro cultures of wild cherry, chestnut and oak. Annals of Science 52: 287-293.

[32]. G Sujatha, and BD Ranjitha Kumari. 2008. Micropropagation, encapsulation and growth of Artemesia vulgaris node explant for germplasm preservation. South African Journal of Botany 74: 93-100.

[33]. SK Naik, and PK Chand 2006. Nutrient-alginate encapsulation of in-vitro nodal segments of promegranate (Punica granatum L.) for germplasm distribution and exchange. Scientia Horticulturae 108: 247.

[34]. R Geetha, GV Gopal, and MH Niranjan. 2009. In vitro response of encapsulated shoot tips of Spilanthes acmella. Journal of Basic and Applied Biology 3(1\&2): 82-86.

Table-1: Effect of different concentrations of alginate on germination of synthetic seeds of A. vulgaris.

\begin{tabular}{|c|c|c|c|}
\hline Alginate (\%) & No. of Seeds cultured & $\begin{array}{c}\text { No. of seeds } \\
\text { germinated }\end{array}$ & Germination (\%) \\
\hline 2 & 64 & 54 & 84.37 \\
\hline 3 & 64 & 42 & 65.62 \\
\hline 4 & 64 & 34 & 53.12 \\
\hline
\end{tabular}

Table 2: Effect of storage period and temperature on shoot emergence from encapsulated somatic embryos of $A$. vulgaris.

\begin{tabular}{|c|c|c|}
\hline Storage period (months) & Temperature $\mathbf{(}^{\mathbf{0}} \mathbf{C}$ & Conversion frequency (\%) \\
\hline 01 & 4 & $64.3 \pm 1.76$ \\
\hline 01 & 20 & $71.0 \pm 0.68$ \\
\hline 01 & 22 & $88.7 \pm 0.13$ \\
\hline 02 & 4 & $48.2 \pm 0.05$ \\
\hline 02 & 20 & $57.4 \pm 1.23$ \\
\hline 02 & 22 & $69.3 \pm 0.67$ \\
\hline 04 & 4 & $42.1 \pm 1.43$ \\
\hline 04 & 20 & $52.7 \pm 0.87$ \\
\hline 04 & 22 & $61.4 \pm 0.54$ \\
\hline
\end{tabular}

Table 3: Effect of storage period on germination of encapsulated embryos of $A$. vulgaris

\begin{tabular}{|c|c|c|c|}
\hline Days of Storage & No. of capsule cultured & $\begin{array}{c}\text { No. of capsule } \\
\text { germinated }\end{array}$ & Germination (\%) \\
\hline 0 & 82 & 79 & 96.34 \\
\hline 1 & 64 & 59 & 92.18 \\
\hline 3 & 48 & 45 & 93.18 \\
\hline 5 & 72 & 63 & 87.5 \\
\hline 7 & 68 & 49 & 72.05 \\
\hline 10 & 73 & 42 & 57.53 \\
\hline 15 & 77 & 39 & 50.64 \\
\hline 18 & 79 & 35 & 44.30 \\
\hline 20 & 80 & 28 & 35 \\
\hline 25 & 71 & 21 & 29.57 \\
\hline
\end{tabular}

Table 4: Effect of growth regulators on artificial seed germination and shoot length on MS medium

\begin{tabular}{|c|c|c|c|c|}
\hline \multirow{3}{*}{ Growth regulators } & \multicolumn{5}{|c|}{ Artemisia vulgaris } \\
\cline { 2 - 5 } & Concentration (mg-1) & $\begin{array}{c}\text { Days to } \\
\text { germinate }\end{array}$ & $\begin{array}{c}\text { Germination (\%) } \\
\text { Shoot length (cm) } \\
\text { (Mean } \pm \text { SD) }\end{array}$ & $1.24 \pm 0.051$ \\
\hline \multirow{2}{*}{ Control } & MS & $4-5$ & 60 & $1.78 \pm 0.83$ \\
\hline \multirow{2}{*}{ BAP } & 0.5 & $3-4$ & 63 & $2.01 \pm 0.071$ \\
\cline { 2 - 5 } & 1.0 & $4-6$ & 80 & $2.53 \pm 0.34$ \\
\cline { 2 - 5 } & 1.5 & $5-7$ & 81 & $1.05 \pm 0.068$ \\
\cline { 2 - 5 } & 2.0 & $4-7$ & 45 & $1.31 \pm 0.081$ \\
\cline { 2 - 5 } & $0.5+0.5$ & $5-5$ & 47 & $1.65 \pm 0.051$ \\
\cline { 2 - 5 } & $0.5+1.5$ & $4-6$ & 79 & $2.06 \pm 0.113$ \\
\cline { 2 - 5 } & $0.5+2.0$ & $3-6$ & 50 & $1.74 \pm 0.150$ \\
\cline { 2 - 5 } & $1.0+0.5$ & $3-7$ & 65 & $1.80 \pm 0.075$ \\
\hline
\end{tabular}


In vitro regeneration of multiple shoots from encapsulated somatic embryos of Artemisia vulgaris $L$.

\begin{tabular}{|c|c|c|c|c|}
\hline & $1.0+1.5$ & $4-6$ & 80 & $2.14 \pm 0.127$ \\
\hline & $1.0+2.0$ & $5-7$ & 87 & $3.19 \pm 0.261$ \\
\hline \multirow[t]{4}{*}{ Kn } & 0.5 & 5-7 & 20 & $0.09 \pm 0.178$ \\
\hline & 1.0 & $4-6$ & 49 & $1.24 \pm 0.278$ \\
\hline & 1.5 & $4-6$ & 50 & $1.72 \pm 0.09$ \\
\hline & 2.0 & $3-4$ & 81 & $2.00 \pm 0.07$ \\
\hline \multirow[t]{4}{*}{$\mathrm{GA}_{3}$} & 0.5 & $3-7$ & 63 & $1.15 \pm 0.051$ \\
\hline & 1.0 & $3-6$ & 65 & $1.82 \pm 0.078$ \\
\hline & 1.5 & $3-6$ & 80 & $2.19 \pm 0.091$ \\
\hline & 2.0 & $4-7$ & 81 & $2.71 \pm 0.074$ \\
\hline \multirow[t]{4}{*}{$\mathrm{BAP}+\mathrm{GA}_{3}$} & $0.5+0.5$ & $4-6$ & 59 & $1.75 \pm 0.150$ \\
\hline & $0.5+1.0$ & $4-5$ & 65 & $1.80 \pm 0.075$ \\
\hline & $1.0+0.5$ & $4-6$ & 80 & $2.14 \pm 0.127$ \\
\hline & $1.0+1.0$ & $6-7$ & 89 & $3.19 \pm 0.261$ \\
\hline \multirow{3}{*}{$\begin{array}{c}\text { GA3+IAA+ } \\
\text { Ascorbic Acid }\end{array}$} & $0.5+0.5+40$ & $5-7$ & 80 & $2.50 \pm 0.180$ \\
\hline & $1.0+0.5+40$ & $4-6$ & 85 & $3.33 \pm 0.192$ \\
\hline & $1.5+0.5+40$ & $4-5$ & 90 & $4.10 \pm 0.325$ \\
\hline
\end{tabular}
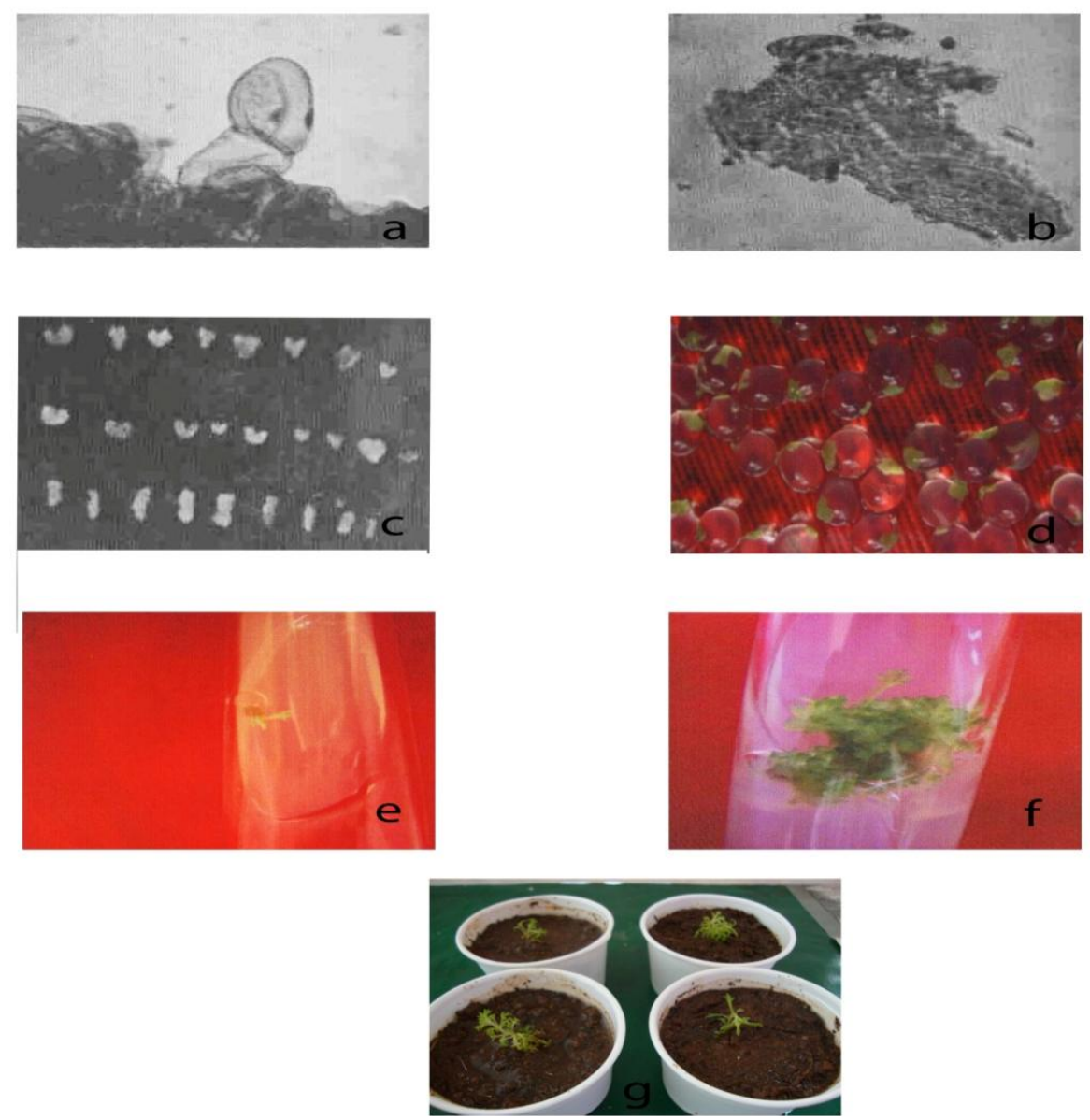

Fig. 1 (a-g): Suspension culture: Plant regeneration and multiple shoot formation synthetic seeds of $A$. vulgaris.

\section{Figure Legends:}

a. Two-celled proembryo

b. Bipolar embryo

c. Various stages of embryoids

d. Synthetic seed

e. Germination of synthetic seed

f. Multiple shoots from single synthetic seeds

g. Hardened potted 